Article

\title{
A Generalized Maximum Entropy Stochastic Frontier Measuring Productivity Accounting for Spatial Dependency
}

\author{
Axel Tonini ${ }^{1, *}$ and Valerien Pede ${ }^{2}$ \\ 1 LEI, Part of Wageningen UR, PO Box 29703, The Hague 2585 DB, The Netherlands \\ 2 International Rice Research Institute, DAPO Box 7777, Metro Manila 1301, The Philippines; \\ E-Mail: v.pede@cgiar.org
}

* Author to whom correspondence should be addressed: E-Mail: axel.tonini@wur.nl; Tel.: +31-0-70-3358322; Fax: +31-0-70-3615624.

Received: 29 September 2011; in revised form: 17 October 2011 / Accepted: 24 October 2011 / Published: 28 October 2011

\begin{abstract}
In this paper, a stochastic frontier model accounting for spatial dependency is developed using generalized maximum entropy estimation. An application is made for measuring total factor productivity in European agriculture. The empirical results show that agricultural productivity growth in Europe is driven by upward movements of technology over time through technological developments. Results are then compared for a situation in which spatial dependency in the technical inefficiency effects is not accounted.
\end{abstract}

Keywords: stochastic frontier; spatial dependency; generalized maximum entropy

PACS Codes: 89.65.Gh; 89.70.Cf

\section{Introduction}

This paper develops a stochastic frontier model accounting for spatial dependency through spatial econometrics techniques and using generalized maximum entropy (GME) estimation. An application is provided computing Total Factor Productivity (TFP) growth for the agricultural sector of the EU-27 countries as well as three European Union (EU) candidate countries (CC): Croatia. Former Yugoslav Republic of Macedonia (FYROM) and Turkey. 
Stochastic frontiers, simultaneously introduced by Aigner [1], Meeusen [2] and Battese [3], usually comprise dual error components, one accounting for the random error and the other for the technical inefficiency. In order to compute total factor productivity growth a time-varying inefficiency model is usually required [4]. A farm-specific temporal variation in technical inefficiency as developed by Cuesta [5] is applied to allow countries to have different temporal technical inefficiency patterns.

Spatial dependence is accounted for in the technical inefficiency component of the stochastic frontier. In the literature, [6] detected that the employment rate exhibits a correlation with economic growth in neighbouring counties in the American Midwest, while [7] found that technical efficiency scores can display spatial dependency given that their determinants are often spatially correlated. Therefore, it important to account for the spatial dependency between countries since economic conditions in neighbouring countries are likely to be similar as a result of spillovers of economic activities across borders and even more for the countries that are part of the EU. These knowledge externalities can create dependency in the technical efficiency. Moreover, several other unobserved or immeasurable characteristics may be similar across country boundaries, which may lead to dependency in the residuals of empirical models of technical efficiency. The spatial dependency is introduced through a spatial weight matrix exogenously defined to capture the spillover effects between countries included in the study. In so doing, the technical inefficiency component is allowed to follow a spatially autoregressive error process [8].

Standard maximum likelihood stochastic frontier estimations require ad-hoc assumptions on the distribution of the inefficiency component. The GME estimator avoids the need for making unnecessary assumptions on the inefficiency component. Maximum entropy estimators were introduced by Golan [9], and proved to be robust under ill-posed and ill-conditioned problems. A GME is particularly suited in this context given the very large number of parameters to be estimated. The data are from the Food and Agriculture Organization (FAO) for the period 1993-2006 comprising former EU-15 countries, EU-12 as well as three CC.

The paper is structured as follows: Section 2 contains the time-varying technical inefficiency stochastic frontier model accounting for spatial dependency. Section 3 describes the data and the empirical model. Section 4 presents the empirical results. Finally, in Section 5 we provide our conclusions.

\section{The Empirical Model}

A stochastic production frontier is estimated in order to compute TFP growth which measures the change in total output relative to changes in the use of all inputs. Approaches using stochastic-frontier production functions have been independently proposed by Aigner [1], Meeusen [2] and Battese [3]. Schmidt [10] extended to panel data the production frontier model. For a stochastic production frontier estimated by GME see Macedo [11]. The agricultural production of country $i(i=1, \ldots, N)$ at time $t(t=1, \ldots, T), Y_{i t}$, is assumed to be produced using the input array, $\mathbf{X}_{i t}$ constituted by land $\left(X_{1 i t}\right)$, machinery $\left(X_{2 i t}\right)$, labor $\left(X_{3 i t}\right)$, fertilizer $\left(X_{4 i t}\right)$ and livestock $\left(X_{5 i t}\right)$ respectively.

A trascendetal logarithmic (i.e. translog) production frontier is selected for its flexibility in measuring TFP growth. It provides a second-order differential approximation which is linear in parameters. A translog production frontier allows production elasticities to vary at each data point and 
non-neutral Hicksian technical change. The empirical model is specified following the 'true' fixed effects model of Greene [12,13]. The 'true' fixed effects model allows to capture potential country-specific time invariant heterogeneity. However when the number of time periods available in each panel is not large enough the 'true'fixed effects model may be subject to the incidental parameter problem. Countries can be characterized by different stage of development, liberalization and different conditions in terms of soil quality, drainage, altitude and climate. The empirical model is specified as follows:

$$
y_{i t}=\alpha_{i}+\sum_{n=1}^{N} \beta_{n} x_{i t n}+\beta_{t} t+\frac{1}{2} \sum_{n=1}^{N} \sum_{m=1}^{N} \beta_{n m} x_{i t n} x_{i t m}+\frac{1}{2} \beta_{t t} t^{2}+\sum_{n=1}^{N} \beta_{n t} x_{i t n} t-Z_{i t}+\varepsilon_{i t}
$$

where lower case letters $(y, x)$ indicate natural logs of upper case letters $(Y, X), \boldsymbol{\alpha}_{i}=\left(\alpha_{0}, \alpha_{1}, \ldots, \alpha_{I}\right)$ is the vector of country-specific intercepts capturing time invariant heterogeneity, $\boldsymbol{\beta}_{\boldsymbol{n}}=\left(\beta_{0}, \beta_{1}, \ldots, \beta_{N}\right)$ is the vector of unknown parameters to be estimated, $t$ a time trend used in order to account for technological change. The inefficiency $Z_{i t}=-\ln \left(\tau_{i t}\right)$ is assigned a non-negative random variable and the random error $\varepsilon_{i t}=\ln \left(\xi_{i t}\right)$ has a symmetric distribution with mean zero.

Regularity conditions are a priori imposed during the estimation to ensure that input elasticities are nonnegative at all observed output levels [14] with the following inequality restrictions:

$$
E_{x_{i t, n}} \equiv \frac{\partial y_{i t}}{\partial x_{i t n}}=\zeta_{i t, n} \geq 0, \text { for } n=1, \ldots, 5
$$

A generalization of the time-varying inefficiency model of Battese [15] proposed by Cuesta [5] is implemented and extended to account for spatial dependency in the technical inefficiency effects. Cuesta's [5] function is specified as:

$$
Z_{i t}=\exp \left[\eta_{i}(t-T)\right] Z_{i}
$$

where the temporal pattern of inefficiency effects (i.e., $\eta_{i}$ ) is now a country-specific parameters responsive to different temporal variations among countries.

Spatial dependency is introduced in the inefficiency terms equation (3) by the following expression:

$$
Z_{i}=\left\lfloor(\mathbf{I}-\rho \mathbf{W})^{-1} \Omega_{i}\right\rfloor
$$

where $\mathbf{I}$ is an identity matrix, $\rho$ the parameter accounting for spatial dependency in the inefficiency effects, $\mathbf{W}$ the spatial weighting matrix and $\Omega_{i}$ a stochastic term ensuring that the technical efficiency $\exp \left(-Z_{i t}\right)$ lies between zero and one. Substituting Equation (4) into (3):

$$
\left.Z_{i t}=\exp \left[\eta_{i}(t-T)\right](\mathbf{I}-\rho \mathbf{W})^{-1} \Omega_{i}\right]
$$

First of all, different weight matrix forms are possible, such as contiguity weights and distance weights. The choice of the weight matrix depends on the study at hand and the subject being investigated. In this study, a distance-based weight matrix is more appropriate because not all countries involved are contiguous (sharing borders). The weight matrix is defined a priori and exogenously based on arc distances between the geographical midpoints of the countries. The neighbourhood is defined using a cut-off distance that enforces all countries to have at least one 
neighbour. Two countries are considered neighbors when the geographical distance (arc distance) between them is less than a threshold distance. The weight matrix therefore takes value one when countries are neighbors and zero when they are not. The threshold distance in this case is chosen in such a way to guarantee all countries have at least one neighbor. No country should be a neighbor to itself. This forces the weight matrix to have zero on the diagonal. The weight matrix is further standardized. Mathematical and statistical reasons for standardization can be found in Bell and Bockstael [16]. The technical efficiency of each country in each year is obtained through the conditional expectation of $\exp \left(-Z_{i t}\right)$, given the value of $\left(\varepsilon_{i t}-Z_{i}\right)$.

TFP growth is computed and decomposed into the efficiency, technical change and scale components through the identity with the so-called Malmquist index (MI) [17]. The MI can be defined by using either an input or an output orientation. For country-level analysis, an output orientation is the proper choice [4]. An output orientation looks for the maximal proportional expansion of an output vector, given an input or resource vector. The efficiency change component is given by:

$$
E C_{i s}=\exp \left(Z_{i t}-Z_{i s}\right)=Z_{i s} / Z_{i t}
$$

The technical change component requires one to evaluate the partial derivatives of the production frontier with respect to time using the data for the $i$-th country in period $s$ and $t$. Then the technical change between the adjacent periods $s$ and $t$ can be derived through the geometric mean of the aforementioned partial derivatives. In the case of a translog specification, this is equivalent to the exponential of the arithmetic mean of the log derivatives as given by:

$$
T C_{i s}=\exp \left\{\frac{1}{2}\left[\frac{\partial y_{i s}}{\partial s}+\frac{\partial y_{i t}}{\partial t}\right]\right\}
$$

To detect potential scale change effects, scale change is introduced in computing TFP following Orea [18], who uses Diewert's quadratic identity to derive a MI. The scale change component is given by:

$$
S C_{i s}=\exp \left\{\frac{1}{2} \sum_{n=1}^{N}\left(\zeta_{i s n} S F_{i s}+\zeta_{i t n} S F_{i t n}\right)\left(x_{i s n} / x_{i t n}\right)\right\}
$$

where $S F_{i s}=\left(\zeta_{i s}-1\right) / \zeta_{i s}, \zeta_{i s}=\sum_{n=1}^{N} \zeta_{i s n}$ (return to scale) and $\zeta_{i s n}=\frac{\partial y_{i s}}{\partial x_{i s n}}$ (input elasticities). Each single component is then summed up to recover the MI of TFP growth.

\section{Data and the Estimation}

Data are drawn from the FAOSTAT database of the Statistics Division of the Food and Agriculture Organization (FAO) of the United Nations. The data include the former EU-15 countries as well as the new member states EU-12, notably: Austria, Belgium-Luxembourg, Denmark, Finland, France, Germany, Greece, Ireland, Italy, The Netherlands, Portugal, Spain, Sweden, and United Kingdom, Bulgaria, Czech Republic, Cyprus, Estonia, Hungary, Latvia, Lithuania, Malta, Poland, Romania, Slovakia, and Slovenia. In addition three CC to the EU accession are considered: Croatia, the Former Yougoslav Republic of Macedonia (FYROM) and Turkey. The data cover the period 1993-2006. The sample includes 29 countries for a period of 14 years yielding 406 observations.

One agricultural aggregate output variable, defined as agricultural production net of quantities of 
various commodities used as feed and seed, is considered. The output series is based on international commodity average prices (1999-2001 1000 I\$) and expressed in a single currency unit. Five input variables are taken into account. Land comprises arable land land and permanent crops and the area for permanent meadows and pastures. It is measured in $1000 \mathrm{Ha}$. Agricultural tractors refers to wheel and crawler or track-laying tractors (excluding garden tractors) used in agriculture without reference to the horsepower of the tractors. It is measured in number (1000 No) of tractors in use. Agricultural population defined as all persons depending for their livelihood on agriculture, hunting, fishing and forestry. It comprises all persons economically active in agriculture as well as their non-working dependents. It is measured in thousands of people (Pe). Fertiliser is an aggregate of Nitrogen $(\mathrm{N})$, Potassium (P) and Phosphate $(\mathrm{K})$ consumed in agriculture and expressed in tonnes of nutrients. Livestock is constructed by aggregating five categories of animals into sheep equivalent. The categories of animals considered are: buffaloes, cattle, pigs, sheep and goats. Numbers of these animals are converted into sheep equivalents (SE) using the same conversion factors as in Coelli [4]. Table 1 presents descriptive statistics for the data.

Table 1. Descriptive statistics, 1993-2006.

\begin{tabular}{cccccc}
\hline Variables & Units & Avg & Min & Max & Std \\
\hline Agr. Output & $\times 10^{3} \mathrm{I} \$$ & 8281701.2 & 53350.0 & 38125640.0 & 9950171.2 \\
Land & $\times 10^{3} \mathrm{Ha}$ & 8335.2 & 9.0 & 41223.0 & 10174.4 \\
Machinery & $\times 10^{3} \mathrm{No}$ & 349.1 & 0.5 & 1900.0 & 458.2 \\
Labour & $\times 10^{3} \mathrm{Pe}$ & 875.9 & 2.0 & 10454.0 & 1854.0 \\
Fertilizer & $\times 10^{3} \mathrm{Mt}$ & 740.6 & 0.9 & 5064.0 & 1019.5 \\
Livestock & $\times 10^{3} \mathrm{SE}$ & 42007.8 & 236.8 & 191956.0 & 50067.3 \\
\hline
\end{tabular}

A GME estimator is used. The advantages and properties of the GME estimator are extensively discussed in Golan [9], Mittelhammer [19] and Perloff [20]. Here we only list the main advantages for the problem at hand. First, the GME estimator efficiently exploits all the information contained in each data point, instead of using moment conditions as done by the more traditional estimators. Second, it is less influenced by outlying observations because of the weighting between signal and noise in the objective function. Third, it is a robust estimator, even when noise is not normally distributed and/or the design matrix exhibits high condition indexes. Multicollinearity is often problematic in stochastic frontier analysis affecting the sign of the estimated coefficients as well as the precision of the estimated coefficients. Fourth, the GME estimator enables the researcher to easily impose prior information on parameters [21]. Finally, the GME estimator does not require strong behavioural assumptions on the underlying data generating process.

The parameters of the stochastic production frontier are reparameterized according to the GME formalism as follows:

$$
\boldsymbol{\beta}_{\boldsymbol{k}}=\sum_{m=1}^{5} p_{k m} v_{k m} \text { and } \eta_{\boldsymbol{i}}=\sum_{u=1}^{3} p_{i u}^{\prime} v_{i u}^{\prime}
$$

with $p_{k m}$ and $p_{i m}^{\prime}$ being the probability vector associated with the stochastic production frontier parameters to be estimated and the temporal pattern of inefficiency effects, $v_{k m}$ and $v_{i m}^{\prime}$ representing their support values. The supports for $v_{k m}$ are initially set to $(-1000,-500,0,500,1000)$ and the 
supports for $v_{i u}^{\prime}$ to $(-0.5,0,0.5)$. The inefficiency terms and random error are defined by:

$$
\Omega_{i}=\sum_{m=1}^{5} w_{i n} g_{i n} \text { and } \boldsymbol{\varepsilon}_{i t}=\sum_{l=1}^{3} w_{i t l}^{\prime} g_{i t l}^{\prime}
$$

with $w_{i n}$ and $w_{\text {inl }}^{\prime}$ being the probability vectors to be estimated and $g_{\text {in }}$ and $g_{\text {itl }}^{\prime}$ representing the support values. With respect to the number of support points, Golan [9] show through simulation experiments that the greatest improvements in the estimate precision is obtained by selecting five or more support values. The number of support values is set to five for the stochastic frontier parameters and the inefficiency terms whereas it is set to three for the random error. For the signal space definition, when the researcher does not know the possible realizations, it is suggested that $\boldsymbol{v}$ be set to be symmetrical around zero with large negative and positive boundaries [22]. The supports for the stochastic terms $\Omega_{i}$ are set following Campbell [23] to $(0,0.005,0.01,0.0015,1)$. The noise support bounds are specified following the widely accepted three sigma rule of Pukelsheim [24], see also Golan [9], defining a uniform zero-centred symmetric distribution with a support space specified as follows: $(-3 \tilde{\tau},-1.5 \tau, 0,1.5 \widetilde{\tau}, 3 \widetilde{\tau})$, where $\widetilde{\tau}$ is the empirical standard deviation of the dependent variable. The parameter $\rho$ accounting for spatial dependency is reparameterized as follows:

$$
\rho=\sum_{m=1}^{5} r_{m} s_{m}
$$

where $r_{m}$ being the probability vector to be estimated and $s_{m}$ representing the support values defining a uniform symmetric distribution with a support space specified as follows: $(0,0.25,0.5,0.75,1)$.

The GME objective function $H$ to maximize is defined as:

$$
\begin{aligned}
H\left(\boldsymbol{p}, \boldsymbol{w}, \boldsymbol{w}^{\prime}, \boldsymbol{r}\right)= & -\sum_{k=1}^{29} \sum_{m=1}^{5} p_{k m} \ln p_{k m}-\sum_{i=1}^{29} \sum_{u=1}^{3} p_{i u}^{\prime} \ln ^{\prime} p_{i u}-\sum_{i=1}^{29} \sum_{n=1}^{5} w_{i n} \ln w_{i n} \\
& -\sum_{i=1}^{29} \sum_{t=1}^{14} \sum_{l=1}^{3} w_{i t l}^{\prime} \ln w_{i t l}^{\prime}-\sum_{m=1}^{5} r_{m} \ln r_{m}
\end{aligned}
$$

subject to Equation (1), Equation (2), Equation (5), and Equations (9-11) and the following adding-up constraints

$$
\sum_{m=1}^{5} p_{k m}=1, \quad \sum_{m=1}^{3} p_{i u}^{\prime}=1, \quad \sum_{n=1}^{5} w_{i n}=1, \quad \sum_{l=1}^{3} w_{i t l}^{\prime}=1, \text { and } \quad \sum_{m=1}^{5} r_{m}=1
$$

for all values of $k, i$ and $t$.

\section{Empirical Results and Discussion}

In this section, we discuss the final estimates. The estimates for the time-varying technical inefficiency stochastic frontier model accounting for spatial dependency estimated by GME, are displayed in Table 2. 
Table 2. Estimated coefficients.

\begin{tabular}{|c|c|c|c|c|c|c|}
\hline Coef & GME1 & Support1 & GME2 & Support2 & GME3 & Support3 \\
\hline$\beta_{1}$ & 0.2005 & $m=(0,0.1,0.2,0.3,0.4)$ & 0.2005 & $m=(0,0.1,0.2,0.3,0.4)$ & 0.2005 & $m=(0,0.1,0.2,0.3,0.4)$ \\
\hline$\beta_{2}$ & 0.1996 & $m=(0,0.1,0.2,0.3,0.4)$ & 0.1996 & $m=(0,0.1,0.2,0.3,0.4)$ & 0.1996 & $m=(0,0.1,0.2,0.3,0.4)$ \\
\hline$\beta_{3}$ & 0.1999 & $m=(0,0.1,0.2,0.3,0.4)$ & 0.1999 & $m=(0,0.1,0.2,0.3,0.4)$ & 0.1999 & $m=(0,0.1,0.2,0.3,0.4)$ \\
\hline$\beta_{4}$ & 0.1991 & $m=(0,0.1,0.2,0.3,0.4)$ & 0.1991 & $m=(0,0.1,0.2,0.3,0.4)$ & 0.1991 & $m=(0,0.1,0.2,0.3,0.4)$ \\
\hline$\beta_{5}$ & 0.2008 & $m=(0,0.1,0.2,0.3,0.4)$ & 0.2008 & $m=(0,0.1,0.2,0.3,0.4)$ & 0.2008 & $m=(0,0.1,0.2,0.3,0.4)$ \\
\hline$\beta_{t}$ & 0.0126 & $m=(-1000,-500,0,500,1000)$ & 0.0126 & $m=(-500,-250,0,250,500)$ & 0.0126 & $m=(-250,-125,0,125,250)$ \\
\hline$\beta_{11}$ & 0.2159 & $m=(-1000,-500,0,500,1000)$ & 0.2159 & $m=(-500,-250,0,250,500)$ & 0.2158 & $m=(-250,-125,0,125,250)$ \\
\hline$\beta_{12}$ & -0.1479 & $m=(-1000,-500,0,500,1000)$ & -0.1478 & $m=(-500,-250,0,250,500)$ & -0.1477 & $m=(-250,-125,0,125,250)$ \\
\hline$\beta_{13}$ & -0.0098 & $m=(-1000,-500,0,500,1000)$ & -0.0098 & $m=(-500,-250,0,250,500)$ & -0.0097 & $m=(-250,-125,0,125,250)$ \\
\hline$\beta_{14}$ & -0.0272 & $m=(-1000,-500,0,500,1000)$ & -0.0272 & $m=(-500,-250,0,250,500)$ & -0.0271 & $m=(-250,-125,0,125,250)$ \\
\hline$\beta_{15}$ & 0.1382 & $m=(-1000,-500,0,500,1000)$ & 0.1382 & $m=(-500,-250,0,250,500)$ & 0.1381 & $m=(-250,-125,0,125,250)$ \\
\hline$\beta_{1 t}$ & 0.0108 & $m=(-1000,-500,0,500,1000)$ & 0.0108 & $m=(-500,-250,0,250,500)$ & 0.0108 & $m=(-250,-125,0,125,250)$ \\
\hline$\beta_{22}$ & 0.1058 & $m=(-1000,-500,0,500,1000)$ & 0.1058 & $m=(-500,-250,0,250,500)$ & 0.1058 & $m=(-250,-125,0,125,250)$ \\
\hline$\beta_{23}$ & 0.1171 & $m=(-1000,-500,0,500,1000)$ & 0.1171 & $m=(-500,-250,0,250,500)$ & 0.1170 & $m=(-250,-125,0,125,250)$ \\
\hline$\beta_{24}$ & -0.0419 & $m=(-1000,-500,0,500,1000)$ & -0.0419 & $m=(-500,-250,0,250,500)$ & -0.0419 & $m=(-250,-125,0,125,250)$ \\
\hline$\beta_{25}$ & 0.0661 & $m=(-1000,-500,0,500,1000)$ & 0.0661 & $m=(-500,-250,0,250,500)$ & 0.0660 & $m=(-250,-125,0,125,250)$ \\
\hline$\beta_{2 t}$ & 0.0066 & $m=(-1000,-500,0,500,1000)$ & 0.0066 & $m=(-500,-250,0,250,500)$ & 0.0066 & $m=(-250,-125,0,125,250)$ \\
\hline$\beta_{33}$ & 0.0185 & $m=(-1000,-500,0,500,1000)$ & 0.0184 & $m=(-500,-250,0,250,500)$ & 0.0184 & $m=(-250,-125,0,125,250)$ \\
\hline$\beta_{34}$ & -0.0539 & $m=(-1000,-500,0,500,1000)$ & -0.0539 & $m=(-500,-250,0,250,500)$ & -0.0539 & $m=(-250,-125,0,125,250)$ \\
\hline$\beta_{35}$ & -0.0667 & $m=(-1000,-500,0,500,1000)$ & -0.0667 & $m=(-500,-250,0,250,500)$ & -0.0667 & $m=(-250,-125,0,125,250)$ \\
\hline$\beta_{3 t}$ & -0.0100 & $m=(-1000,-500,0,500,1000)$ & -0.0100 & $m=(-500,-250,0,250,500)$ & -0.0100 & $m=(-250,-125,0,125,250)$ \\
\hline$\beta_{44}$ & 0.0228 & $m=(-1000,-500,0,500,1000)$ & 0.0228 & $m=(-500,-250,0,250,500)$ & 0.0229 & $m=(-250,-125,0,125,250)$ \\
\hline$\beta_{45}$ & 0.1690 & $m=(-1000,-500,0,500,1000)$ & 0.1689 & $m=(-500,-250,0,250,500)$ & 0.1688 & $m=(-250,-125,0,125,250)$ \\
\hline$\beta_{4 t}$ & -0.0064 & $m=(-1000,-500,0,500,1000)$ & -0.0064 & $m=(-500,-250,0,250,500)$ & -0.0064 & $m=(-250,-125,0,125,250)$ \\
\hline$\beta_{55}$ & -0.4092 & $m=(-1000,-500,0,500,1000)$ & -0.4091 & $m=(-500,-250,0,250,500)$ & -0.4087 & $m=(-250,-125,0,125,250)$ \\
\hline$\beta_{5 t}$ & -0.0012 & $m=(-1000,-500,0,500,1000)$ & -0.0012 & $m=(-500,-250,0,250,500)$ & -0.0012 & $m=(-250,-125,0,125,250)$ \\
\hline$\beta_{t t}$ & -0.0017 & $m=(-1000,-500,0,500,1000)$ & -0.0017 & $m=(-500,-250,0,250,500)$ & -0.0017 & $m=(-250,-125,0,125,250)$ \\
\hline$\rho$ & 0.5001 & $m=(0,0.25,0.5,0.75,1)$ & 0.5001 & $m=(0,0.25,0.5,0.75,1)$ & 0.5001 & $m=(0,0.25,0.5,0.75,1)$ \\
\hline
\end{tabular}

All variables, before estimation, are rescaled in order to have unit means so that the estimated first-order coefficients represent the elasticities of output with respect to inputs when evaluated at the variable means. One of the advantages of maximum entropy is that it allows to include prior information on parameters either introducing additional consistency constraints characterizing the system at hand or modifying the support values of the parameters to be estimated. Three different support spaces are specified for the estimated models (GME1, GME2, and GME3). The support space for the first order coefficients is kept fixed at $m=(0,0.1,0.2,0.3,0.4)$ since we attribute a prior expectation of 0.2 to all five first order coefficients in order to fulfill globally monotonicity ensuring a well behaved production frontier function. For the remaining coefficients the supports bounds are progressively shrinked although keeping a wide support definition introducing minimal prior information on the coefficient to be estimated. The estimated coefficients appear to be stable to different choices of support values. The first order coefficient of the time trend variable provides information on the average annual rate in neutral technical change. The annual percentage change in output due to technical change is estimated to be 1.3 percent. The coefficient of time squared is 
negative indicating that the rate of technical change is increasing at a decreasing rate through time. The coefficient of time interacted with the land, machinery, labour, fertilizer and livestock input are positive for the first two input variables and negative for the remaining three input variables. This suggests that technical change has been land-, machinery-saving but labour-, fertilizer- and livestockusing over the time considered. The country-specific intercepts and the coefficients capturing the temporal variation of the technical inefficiency for the estimated model are not reported to save space but are available upon request.

Table 3. Estimated technical efficiency scores for 2006.

\begin{tabular}{|c|c|c|c|c|c|}
\hline Countries & GME1A & Support1 & Countries & GME1B & Support2 \\
\hline Austria & 0.80499 & $w=(0.0 .005 .0 .010 .0 .015 .1)$ & Austria & 0.86293 & $w=(0.0 .005 .0 .010 .0 .015 .0 .67)$ \\
\hline Denmark & 0.80447 & $w=(0.0 .005 .0 .010 .0 .015 .1)$ & Denmark & 0.86261 & $w=(0.0 .005 .0 .010 .0 .015 .0 .67)$ \\
\hline Greece & 0.80180 & $w=(0.0 .005 .0 .010 .0 .015 .1)$ & Greece & 0.86062 & $w=(0.0 .005 \cdot 0.010 .0 .015 .0 .67)$ \\
\hline Germany & 0.80153 & $w=(0.0 .005 .0 .010 .0 .015 .1)$ & Germany & 0.86052 & $w=(0.0 .005 .0 .010 .0 .015 .0 .67)$ \\
\hline Finland & 0.79926 & $w=(0.0 .005 .0 .010 .0 .015 .1)$ & Finland & 0.85875 & $w=(0.0 .005 \cdot 0.010 .0 .015 .0 .67)$ \\
\hline Sweden & 0.79923 & $w=(0.0 .005 .0 .010 .0 .015 .1)$ & Sweden & 0.85874 & $w=(0.0 .005 \cdot 0.010 \cdot 0.015 .0 .67)$ \\
\hline France & 0.79763 & $w=(0.0 .005 .0 .010 .0 .015 .1)$ & France & 0.85758 & $w=(0.0 .005 .0 .010 .0 .015 .0 .67)$ \\
\hline Italy & 0.79735 & $w=(0.0 .005 .0 .010 .0 .015 .1)$ & Italy & 0.85736 & $w=(0.0 .005 .0 .010 .0 .015 .0 .67)$ \\
\hline Netherlands & 0.79659 & $w=(0.0 .005 .0 .010 .0 .015 .1)$ & Netherlands & 0.85682 & $w=(0.0 .005 .0 .010 .0 .015 .0 .67)$ \\
\hline Belgium & 0.79392 & $w=(0.0 .005 .0 .010 .0 .015 .1)$ & Belgium & 0.85504 & $w=(0.0 .005 .0 .010 .0 .015 .0 .67)$ \\
\hline Ireland & 0.75978 & $w=(0.0 .005 .0 .010 .0 .015 .1)$ & Ireland & 0.82970 & $w=(0.0 .005 \cdot 0.010 \cdot 0.015 \cdot 0.67)$ \\
\hline Portugal & 0.75977 & $w=(0.0 .005 .0 .010 .0 .015 .1)$ & Portugal & 0.82970 & $w=(0.0 .005 \cdot 0.010 \cdot 0.015 \cdot 0.67)$ \\
\hline Spain & 0.75973 & $w=(0.0 .005 .0 .010 .0 .015 .1)$ & Spain & 0.82968 & $w=(0.0 .005 \cdot 0.010 .0 .015 .0 .67)$ \\
\hline United Kingdom & 0.75968 & $w=(0.0 .005 .0 .010 .0 .015 .1)$ & United Kingdom & 0.82966 & $w=(0.0 .005 .0 .010 .0 .015 .0 .67)$ \\
\hline Slovakia & 0.80520 & $w=(0.0 .005 .0 .010 .0 .015 .1)$ & Slovakia & 0.86310 & $w=(0.0 .005 .0 .010 .0 .015 .0 .67)$ \\
\hline Poland & 0.80483 & $w=(0.0 .005 .0 .010 .0 .015 .1)$ & Poland & 0.86283 & $w=(0.0 .005 .0 .010 .0 .015 .0 .67)$ \\
\hline Hungary & 0.80473 & $w=(0.0 .005 .0 .010 .0 .015 .1)$ & Hungary & 0.86275 & $w=(0.0 .005 \cdot 0.010 .0 .015 .0 .67)$ \\
\hline Czech Republic & 0.80462 & $w=(0.0 .005 .0 .010 .0 .015 .1)$ & Czech Republic & 0.86268 & $w=(0.0 .005 \cdot 0.010 \cdot 0.015 \cdot 0.67)$ \\
\hline Slovenia & 0.80454 & $w=(0.0 .005 .0 .010 .0 .015 .1)$ & Romania & 0.86265 & $w=(0.0 .005 .0 .010 .0 .015 .0 .67)$ \\
\hline Romania & 0.80454 & $w=(0.0 .005 .0 .010 .0 .015 .1)$ & Slovenia & 0.86261 & $w=(0.0 .005 \cdot 0.010 \cdot 0.015 .0 .67)$ \\
\hline Malta & 0.80235 & $w=(0.0 .005 .0 .010 .0 .015 .1)$ & Malta & 0.86102 & $w=(0.0 .005 .0 .010 .0 .015 .0 .67)$ \\
\hline Bulgaria & 0.80212 & $w=(0.0 .005 .0 .010 .0 .015 .1)$ & Bulgaria & 0.86084 & $w=(0.0 .005 \cdot 0.010 \cdot 0.015 .0 .67)$ \\
\hline Lithuania & 0.80070 & $w=(0.0 .005 .0 .010 .0 .015 .1)$ & Lithuania & 0.85981 & $w=(0.0 .005 .0 .010 \cdot 0.015 .0 .67)$ \\
\hline Latvia & 0.80002 & $w=(0.0 .005 .0 .010 .0 .015 .1)$ & Latvia & 0.85932 & $w=(0.0 .005 .0 .010 .0 .015 .0 .67)$ \\
\hline Estonia & 0.79925 & $w=(0.0 .005 .0 .010 .0 .015 .1)$ & Estonia & 0.85875 & $w=(0.0 .005 \cdot 0.010 \cdot 0.015 .0 .67)$ \\
\hline Cyprus & 0.79803 & $w=(0.0 .005 .0 .010 .0 .015 .1)$ & Cyprus & 0.85785 & $w=(0.0 .005 .0 .010 .0 .015 .0 .67)$ \\
\hline Croatia & 0.80490 & $w=(0.0 .005 .0 .010 .0 .015 .1)$ & Croatia & 0.86287 & $w=(0.0 .005 .0 .010 .0 .015 .0 .67)$ \\
\hline FYROM & 0.80440 & $w=(0.0 .005 .0 .010 .0 .015 .1)$ & FYROM & 0.86256 & $w=(0.0 .005 \cdot 0.010 .0 .015 .0 .67)$ \\
\hline Turkey & 0.79041 & $w=(0.0 .005 .0 .010 .0 .015 .1)$ & Turkey & 0.85228 & $w=(0.0 .005 \cdot 0.010 \cdot 0.015 \cdot 0.67)$ \\
\hline Standard Deviation & 0.01496 & & Standard Deviation & 0.01100 & \\
\hline
\end{tabular}

Table 3 presents the estimated technical efficiency scores assuming two different upper bounds in the support of the inefficiency component. Following Campbell [23] we estimated two models (GME1A and GME1B) where the upper limit for the support points is changed. The model GME1A assumes a prior technical efficiency mean of 81.4 percent with a maximum of efficiency of 100 
percent and a minimum of 36.8 percent. The model GME1B assumes a prior technical efficiency mean of 86.9 percent with a maximum of efficiency of 100 percent and a minimum of 51.2 percent. The ranking of the technical efficiency scores is preserved under the two different distributional assumptions with the exception made for Romania and Slovenia. GME1A displays higher standard deviation in the estimates and a larger entropy value.

The decomposition of TFP growth for each country is presented in Table 4. On average the EU-12 is characterized by higher agricultural productivity growth rates as compared to EU-15 and CC. TFP growth ranges from 0.48 for Turkey to 3.48 for Slovenia. All the countries under analysis showed productivity growth. Efficiency change ranges from -0.20 for Belgium to 0.17 for Germany. Technical change ranges from -0.34 for Croatia to 2.49 for Slovenia. Scale change ranges from -0.68 for France to 2.87 for Malta. The estimates suggest that productivity growth was driven by technical change. The estimates of technical efficiency change were then compared with a model not allowing for spatial dependency $(\rho=0)$. In Figure 1 cumulated technical efficiency change is reported for the model allowing for spatial dependency and for the more standard model not including spatial dependency. From this application, it appears that not accounting for spatial dependency has an impact on the final technical inefficiency estimates. The cumulated technical efficiency changes appear underestimated in the standard model not accounting for spatial dependency.

Figure 1. Cumulated technical efficiency changes, (percent).

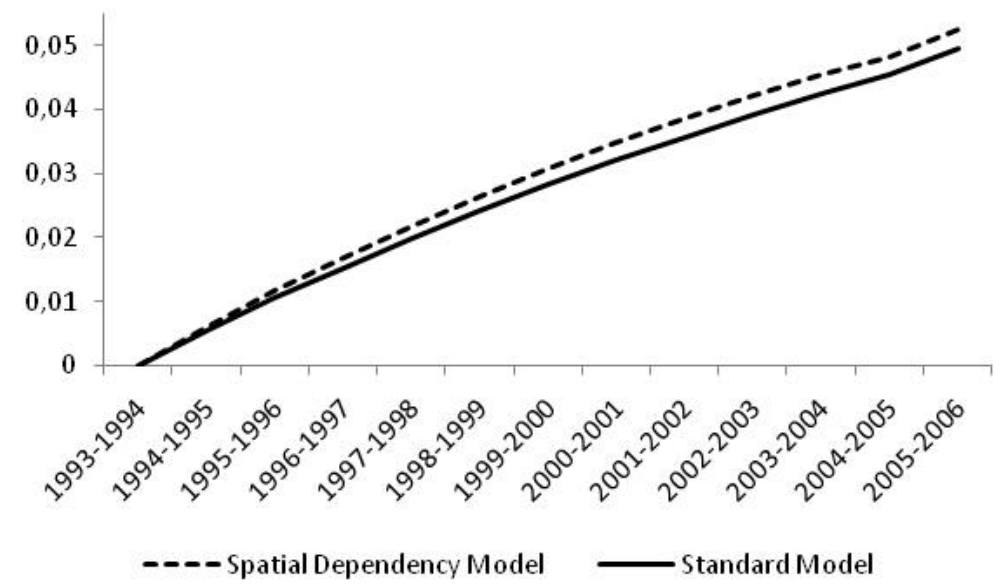

Table 4. Decomposition of TFP growth for 2006, (percent).

\begin{tabular}{ccccc}
\hline Countries & Efficiency Change & Technical Change & Scale Change & TFP Change \\
\hline Austria & 0.0150 & 2.1045 & -0.1027 & 2.0168 \\
Denmark & 0.1108 & 1.5095 & 0.1393 & 1.7595 \\
Sweden & -0.0479 & 1.8101 & -0.0362 & 1.7259 \\
Spain & 0.0773 & 1.6065 & 0.0086 & 1.6924 \\
Finland & -0.0097 & 1.6997 & -0.0104 & 1.6796 \\
Ireland & 0.0073 & 1.3844 & 0.0069 & 1.3986 \\
United Kingdom & -0.0991 & 1.5839 & -0.2259 & 1.2589 \\
Belgium & -0.1952 & 1.1707 & 0.1765 & 1.1519 \\
France & 0.0504 & 1.7017 & -0.6795 & 1.0725 \\
Italy & -0.0086 & 1.5461 & -0.4885 & 1.0490 \\
Greece & -0.0597 & 1.1068 & -0.0547 & 0.9365 \\
\hline
\end{tabular}


Table 4. Cont.

\begin{tabular}{ccccc}
\hline Countries & Efficiency Change & Technical Change & Scale Change & TFP Change \\
\hline Germany & 0.1686 & 1.2156 & -0.6197 & 0.7645 \\
Portugal & 0.0338 & 0.7013 & -0.0142 & 0.7209 \\
Netherlands & 0.0604 & 0.3225 & 0.2351 & 0.6180 \\
EU-15 average & 0.0074 & 1.3902 & -0.1190 & 1.2747 \\
Slovenia & 0.0345 & 2.4905 & 0.9645 & 3.4894 \\
Estonia & -0.0128 & 1.7539 & 1.2814 & 3.0225 \\
Malta & 0.0565 & -0.0044 & 2.8695 & 2.9216 \\
Latvia & -0.0486 & 1.7321 & 0.7246 & 2.4081 \\
Cyprus & -0.0103 & 0.4935 & 1.2080 & 1.6912 \\
Lithuania & -0.0458 & 1.5618 & 0.0213 & 1.5373 \\
Bulgaria & -0.0289 & 1.3112 & 0.0368 & 1.3192 \\
Slovakia & -0.0666 & 0.4443 & 0.4215 & 0.7992 \\
Hungary & 0.0465 & 0.8790 & -0.1343 & 0.7912 \\
Romania & 0.1022 & 0.8323 & -0.3632 & 0.5714 \\
Poland & -0.0564 & 0.5874 & 0.0009 & 0.5319 \\
Czech Republic & -0.0620 & 0.5649 & -0.0184 & 0.4846 \\
EU-12 average & -0.0076 & 1.0539 & 0.5844 & 1.6306 \\
Fyrom & 0.1146 & 1.8425 & 0.3255 & 2.2826 \\
Croatia & 0.0089 & -0.3494 & 1.3851 & 1.0446 \\
Turkey & -0.0187 & 0.1320 & 0.3707 & 0.4841 \\
CC average & 0.0349 & 0.5417 & 0.6937 & 1.2704 \\
\hline
\end{tabular}

\section{Conclusions}

A time-varying technical inefficiency stochastic frontier model was developed accounting for spatial dependency through spatial econometrics techniques and using a GME estimation procedure. The estimated model also controlled for country-specific time invariant heterogenity. An application was provided computing total factor productivity growth for the agricultural sector of the EU-27 countries as well as three CC: Croatia, FYROM and Turkey.

The GME estimator allowed us to estimate a model with a relatively large number of parameters and include prior information on parameters by defining support bounds and adding specific consistency constraints. The inclusion of prior information helped in decreasing multicollinearity issues among the exogenous variables The economic analysis showed that agricultural productivity growth in Europe is driven by upward movements of technology over time through technological developments. EU-12 countries are characterized by larger agricultural productivity growth rates as compared to the EU-15 countries and the CC. Most of the countries that were well below the frontier at the beginning of the sample period are displaying high TFP growth rates evidencing catch-up. The empirical results show that not allowing for spatial dependency underestimate the cumulated technical inefficiency changes.

Topics for future research are the programming of standard errors with bootstrapping techniques and to examine the consistency properties of the GME estimator. Care should be taken when interpreting the results since the input data used did not allow to control for differences in input 
qualities across countries. In additon, the potential incidental parameter problem and related bias should be limited in our application given the relatively large number of time periods available in our panel data set.

\section{References}

1. Aigner, D.J.; Lovell, C.A.K.; Schmidt, P.J. Formulation and estimation of stochastic frontier production function models. J. Econom. 1977, 6, 21-37.

2. Meeusen, W.; van den Broeck, J. Efficiency estimation from Cobb-Douglas production functions with composed error. Int. Econ. Rev. 1977, 18, 435-444.

3. Battese, G.E.; Corra, G. Estimation of a production frontier model with application to the pastoral zone of Easter Australia. Aust. J. Agric. Econ. 1977, 21, 167-179.

4. Coelli, T.J.; Prasada Rao, D.S.; O’Donnell, C.G.; Battese, G.E. An Introduction to Efficiency and Productivity Analysis, 2nd ed.; Kluwer Academic: Boston, MA, USA, 2005; p. 367.

5. Cuesta, R. A production model with firm specific temporal variation in technical efficiency: With application to Spanish dairy farms. J. Prod. Anal. 2000, 13, 139-158.

6. Monchuk, D.C.; Miranovski, J.A. Spatial Labor Market and Technology Spillovers-Analysis from US Midwest, No. 22250. In Proceedings of the 2003 Annual Meeting, Montreal, Canada, 27-30 July 2003.

7. Druska, V.; Horrace, W.C. Generalized moment estimation for spatial panel data: Indonesian rice farming. Am. J. Agric. Econ. 2004, 86, 185-198.

8. Anselin, L. Spatial Econometrics: Methods and Models, 1st ed.; Kluver: London, UK, 1988; p. 304.

9. Golan, A.; Judge, J.; Miller, D. Maximum Entropy Econometrics: Robust Estimation with Limited Data, 1st ed.; John Wiley and Sons: Chichester, UK, 1996; p. 324.

10. Schmidt, P.; Sickles R.C. Production frontier and panel data. J. Bus. Econ. Stat. 1984, 2, 299-326.

11. Macedo, P.; Silva, E. A stochastic production frontier model with a translog specification using the generalized maximum entropy estimator. Econ. Bull. 2010, 1, 587-596.

12. Greene, W.H. Distinguishing between heterogeneity and inefficiency: Stochastic frontier analysis of the World Health Organization's panel data on national health care systems. Health Econ. 2004, 13, 959-980.

13. Greene, W.H. Fixed and random effects in stochastic frontier models. J. Prod. Anal. 2005, 23, $7-32$.

14. Terrell, D. Incorporating monotonicity and concavity conditions in flexible functional forms? J. Appl. Econ. 1996, 11, 179-194.

15. Battese, G.E.; Coelli, T. Frontier production functions, technical efficiency and panel data: With application to paddy farmers in India. J. Prod. Anal. 1992, 3, 153-169.

16. Bell, K.P.; Bockstael, N.E. Applying the generalized-moments estimation approach to spatial problems involving micro-level data. Rev. Econ. Statictics 2000, 82, 72-82.

17. Caves, D.W.; Christensen, L.R.; Diewert, W.E. The economic theory of index numbers and the measurement of input, output and productivity. Econometrica 1982, 50, 1393-1414. 
18. Orea, L. Parametric decomposition of a generalized Malmquist index. J. Prod. Anal. 2002, 18, $5-22$.

19. Mittelhammer, R.C.; Judge, G.G.; Douglas, J.M. Econometric Foundations, 1st ed.; Cambridge University Press: Cambridge, UK, 2000; p. 784.

20. Perloff, J.M.; Karp, L.S.; Golan, A. Estimating Market Power and Strategies, 1st ed.; Cambridge University Press: Cambridge, UK, 2007; p. 352.

21. Golan, A.; Perloff, J.M.; Shen, E.Z. Estimating a demand system with non-negativity constraints: Mexican meat demand. Rev. Econ. Statistics 2001, 83, 541-550.

22. Golan, A. Information theoretic approach for estimating nonlinear dynamic models. Stud. Nonlinear Dyn. E 2003, 7, 1-24.

23. Campbell, R.; Rogers, K.; Rezek, J. Efficient frontier estimation: A maximum entropy approach. J. Prod. Anal. 2008, 30, 213-221.

24. Pukelsheim, F. The three sigma rule. Am. Stat. 1994, 48, 88-91.

(C) 2011 by the authors; licensee MDPI, Basel, Switzerland. This article is an open access article distributed under the terms and conditions of the Creative Commons Attribution license (http://creativecommons.org/licenses/by/3.0/). 